Article

\title{
Sleep Duration as the Main Indicator of Self-Rated Wellness and Health among Healthcare Workers Involved in the COVID-19 Pandemic
}

\author{
Maryam Masoumi ${ }^{1}$, Kamyar Shokraee ${ }^{2}$, Somayeh Mohammadi ${ }^{1}$, Soroush Moradi ${ }^{3}$, Mohammad Bagherzade ${ }^{4}$, \\ Javad Balasi ${ }^{5}$ and Abbas Smiley ${ }^{6, *}$ \\ 1 Department of Internal Medicine, Qom University of Medical Science and Health Services, \\ Qom 37169-65384, Iran; m.masoumiy@gmail.com (M.M.); s.mohammadi199620@gmail.com (S.M.) \\ 2 Department of Surgery, Iran University of Medical Sciences, Tehran 14496-14535, Iran; \\ k-shokraee@alumnus.tums.ac.ir \\ 3 Department of Internal Medicine, Tehran University of Medical Sciences, Tehran 14176-53911, Iran; \\ moradi-s@alumnus.tums.ac.ir \\ 4 Shahid Beheshti Hospital, Qom University of Medical Sciences, Qom 37169-65384, Iran; \\ m_bagherzadeh3@yahoo.com \\ 5 School of Medicine, Iran University of Medical Sciences, Tehran 14496-14535, Iran; Javadbalasi8@gmail.com \\ 6 Westchester Medical Center, New York Medical College, New York, NY 10595, USA \\ * Correspondence: Abbas.Smiley@WMChealth.org
}

check for

updates

Citation: Masoumi, M.; Shokraee, K.; Mohammadi, S.; Moradi, S.;

Bagherzade, M.; Balasi, J.; Smiley, A. Sleep Duration as the Main Indicator of Self-Rated Wellness and Health among Healthcare Workers Involved in the COVID-19 Pandemic. Int. J. Environ. Res. Public Health 2022, 19, 136. https://doi.org/10.3390/ ijerph19010136

Academic Editor: Jianyong Wu

Received: 1 November 2021

Accepted: 19 December 2021

Published: 23 December 2021

Publisher's Note: MDPI stays neutral with regard to jurisdictional claims in published maps and institutional affiliations.

Copyright: (c) 2021 by the authors. Licensee MDPI, Basel, Switzerland. This article is an open access article distributed under the terms and conditions of the Creative Commons Attribution (CC BY) license (https:// creativecommons.org/licenses/by/ $4.0 /)$.

\begin{abstract}
Objective: This study was performed during the COVID-19 pandemic to better understand the indicators of self-rated wellness and health among healthcare workers. Methods: Sleep pattern, mood status, nutritional condition, physical activity, habits and the subjective wellness and health index of the healthcare workers of a university affiliated hospital were surveyed. Paired $t$-tests were performed to compare the participants' quality of life before and after the outbreak of COVID-19. Multivariable linear regression models with a backward elimination stepwise process determined the parameters that significantly correlated with self-reported wellness and health. Results: Of the 200 healthcare workers who participated in this study, $119(60 \%)$ were female and $81(40 \%)$ were male, with a mean (SD) age of 28.8 (5.9) years. We found that the COVID-19 pandemic significantly changed many lifestyle factors compared to the pre-pandemic states. The scores of sleep quality, mood status, pre-planned physical activity and social activity were reduced by $30 \%, 40 \%, 50 \%$ and $70 \%$, respectively. The average night sleep duration before the pandemic was $7 \mathrm{~h}$ and $22 \mathrm{~min}$, whereas during the pandemic it decreased to $6 \mathrm{~h}$ and $44 \mathrm{~min}$, a debt of $38 \mathrm{~min}$ in sleep duration every night. As found by multivariable regression modelling, self-reported wellness and health before the pandemic period was associated with wake-up time, mood status, physical activity and diet. During the pandemic period, in addition to these variables, night sleep duration $(\beta=0.049, p=0.049)$ and nap duration ( $\beta=0.009, p=0.01$ ) were left in the final multivariable model and correlated significantly with the wellness and health index. Conclusion: COVID-19 has detrimentally affected healthcare workers' well-being and quality of life. Sleep duration was the main factor correlated with subjective wellness and health index during the current COVID-19 pandemic.
\end{abstract}

Keywords: COVID-19; pandemic; healthcare workers; lifestyle; sleep

\section{Introduction}

Following the emergence of SARS-CoV-2 in December 2019 and the pandemic it caused, healthcare workers' health and well-being came to the spotlight. On the one hand, the drastic change in workplace risks and the tension and anxiety associated with them [1], and on the other hand, the social pressure (and in some contexts, the social exclusion) caused by the unquestionable role of medical professionals in the current pandemic state, threatens their mental health as individuals and their quality of care as professionals [2]. The fear of being a threat to the well-being of vulnerable family members, stigmatization 
of the infected, heavy restriction of workplace flexibility, and strict measurements for disease prevention such as protective masks and gowns all contribute to an increase in depression symptoms and a decline in quality of life among those working in the medical setting $[3,4]$. While many questions about COVID-19 remain unanswered, healthcare workers' well-being in the face of additional workload and increased workplace-associated risks remains a priority. The outcome of this pandemic depends heavily on the medical system's efficiency and maintaining the well-being of healthcare workers is essential to their effectiveness [5]. Being on the lookout for possible signs of excessive pressure among staff and a better understanding of the pandemic's effects on their lifestyle can guide us toward improving their quality of life. Different elements of lifestyle may compromise the wellness and health of healthcare workers. Physical activity [6-12], nutrition [13,14], smoking [15] and mood [16-19] all contribute to their well-being and health status by various degrees and different mechanisms. One of the most important elements of lifestyle is sleep. Chronic sleep debt has been shown to negatively affect wellness and health, as well as healthcare worker performance in terms of clinical errors, mood, motivation, creativity and leadership [20-23]. Herein, we aimed to investigate the lifestyles of healthcare workers during the COVID-19 pandemic and study the parameters that contribute to wellness and health as reported by them.

\section{Methods}

\subsection{Participants}

This cross-sectional study was performed on the healthcare workers of a universityaffiliated hospital including interns and nurses. The university ethics committee approved the protocol of study. Participants were asked to provide a written consent form before their enrolment.

\subsection{Measurements and Data Collection}

In addition to demographical information, a questionnaire addressing subjects' quality and quantity of sleep, mood status and nutritional condition was prepared according to the Mini-Sleep Questionnaire, Gallup Well-Being Index, and Gallup Diet Questionnaire, respectively (Table 1) [24-26]. Nineteen questions evaluated sleep, of which nine were related to sleep duration and ten to sleep quality. Mood status was assessed by five questions, and the nutritional condition was addressed by three other questions. Participants were required to answer each question based on the event's frequency, with 0 meaning that the complaint never happened and 7 meaning that the complaint was present during every day of the week. The sum of the scores of all questions in each part equaled the overall score of each part. A higher overall score indicated a worse quality of life. A similar format of social support questions was constructed [27]. Participants' physical activity was asked about using a modified question from the Brunel Lifestyle Physical Activity Questionnaire [28], indicating their physical activity level per week. Additionally, to account for the detrimental effects of smoking and alcohol on participants' health and wellness, they were questioned in subsequent parts on their level of consumption [29]. Finally, the subjects were required to rate their own wellness and health on a scale of 0 to 20, with 20 being as healthy as possible and 0 being as unhealthy as possible [30]. Table 1 summarizes all the questions with due attention to the section they evaluate. 
Table 1. Lifestyle questionnaire and the parameters assessed by each question.

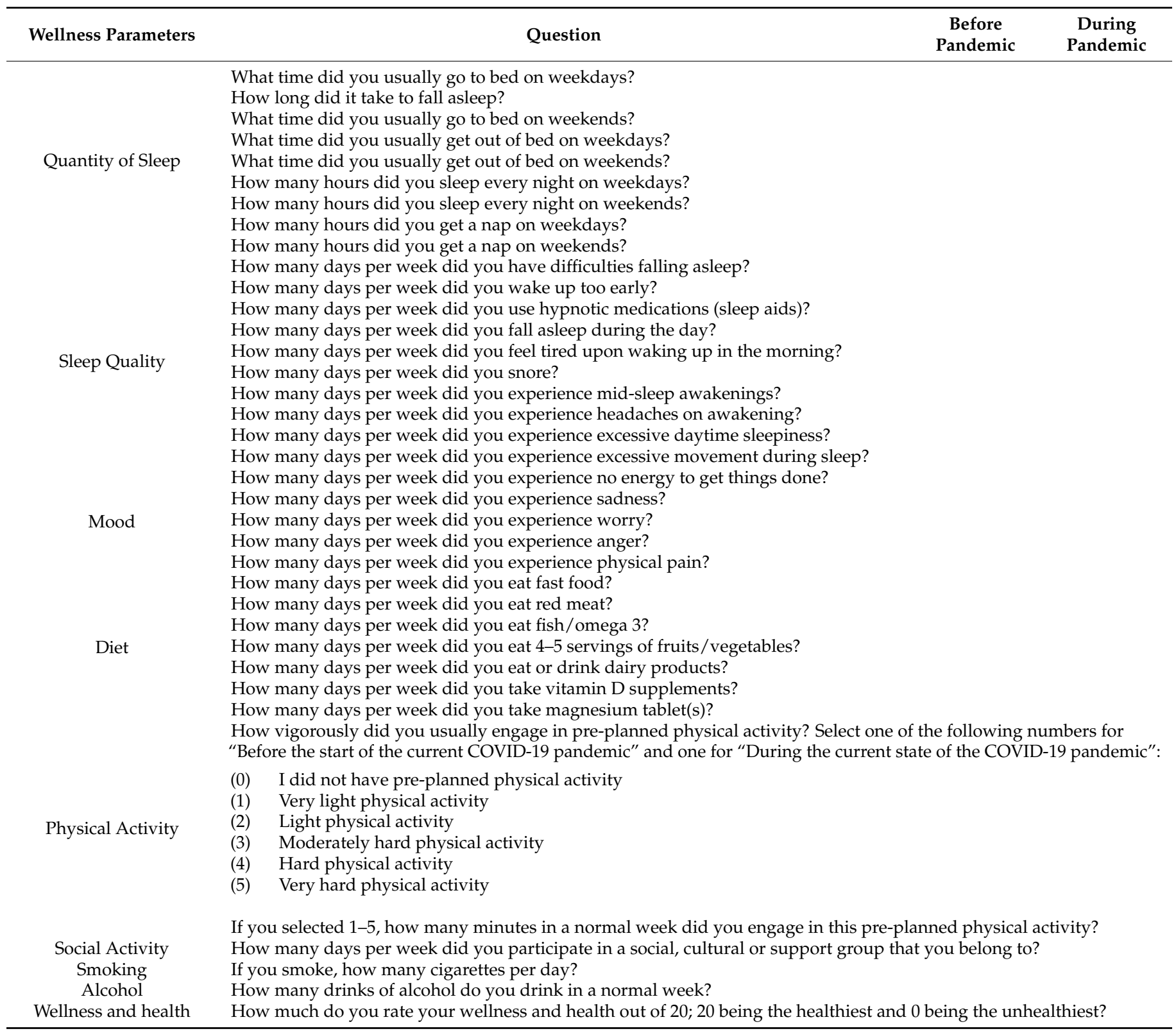

\section{Statistical Analysis}

The frequency distributions of demographic information, wellness and health parameters, lifestyle elements and comorbidities were determined using descriptive analyses. Leven's test was used to assess the normal distribution of the variances. A $t$-test was used to compare continuous variables between males and females because lifestyle factors and self-image could have been significantly different between males and females [31]. A paired $t$-test was used to compare continuous variables between the pre-pandemic and current pandemic periods. Multivariable association of the self-rated wellness and health index and other assessments was assessed through linear regression analysis with a backward stepwise elimination process. Data analyses were conducted using SPSS (version 26, Chicago, IL, USA). A $p$-value of $<0.05$ was considered significant.

\section{Results}

A total of 200 healthcare workers aged 22-50 years old were enrolled in the current study. Their mean (SD) age was 28.8 (5.9) years. A total of 119 subjects were female (60\%). 
The lifestyles of participants are summarized in Table 2. Overall, most elements of lifestyle became worse during the COVID-19 pandemic compared to the pre-pandemic period. Sleep quality, mood, physical activity and social activity were 30\%, 40\%, 50\% and 70\% worse in the pandemic period compared to the pre-pandemic states, respectively. The mean time to go to bed and wake-up time on weekdays in the pandemic were 35 and $24 \mathrm{~min}$ later than those in the pre-pandemic period, respectively. The mean time to go to bed and wake-up time on weekends in the pandemic were 21 and 6 min later than those pre-pandemics, respectively. The self-rated wellness and health index also decreased by $4 \%$ during the current pandemic. The only observed improvement was in the smoking rate (Table 2).

Table 2. Lifestyle characteristics of participants during the pandemic period compared with the pre-pandemic period.

\begin{tabular}{|c|c|c|c|c|c|}
\hline \multirow{2}{*}{ Lifestyle Elements } & \multicolumn{2}{|c|}{ Before Pandemic } & \multicolumn{2}{|c|}{ During Pandemic } & \multirow{2}{*}{$p$ Value } \\
\hline & Mean & SD & Mean & SD & \\
\hline Sleep quality score & 11.84 & 9.27 & 15.24 & 11.48 & 0.0001 \\
\hline Mood score & 8.35 & 8.15 & 11.65 & 9.39 & 0.0001 \\
\hline Diet score & 13.20 & 5.07 & 13.84 & 4.69 & 0.001 \\
\hline Physical activity, minutes & 23.50 & 36.20 & 12.50 & 24.90 & 0.0001 \\
\hline Social activity, days per week & 2.00 & 1.80 & 0.60 & 0.90 & 0.0001 \\
\hline Time to go to bed on weekdays & 24:20 a.m. & $1: 22$ & 24:55 a.m. & $1: 28$ & 0.0001 \\
\hline Time to go to bed on weekends & 1:00 a.m. & $1: 22$ & 1:21 a.m. & $1: 35$ & 0.0001 \\
\hline Time to fall asleep, minutes & 20.50 & 22.50 & 24.00 & 28.30 & 0.013 \\
\hline Wake-up time on weekdays & 7:24 a.m. & $1: 31$ & 7:48 a.m. & $1: 43$ & 0.009 \\
\hline Wake-up time on weekends & 9:00 a.m. & $1: 34$ & 9:06 a.m. & $1: 53$ & 0.342 \\
\hline Night sleep duration on weekdays & 7.36 & 1.68 & 6.73 & 1.69 & 0.274 \\
\hline Night sleep duration on weekends & 7.90 & 1.77 & 7.69 & 1.92 & 0.357 \\
\hline Nap duration on weekdays, minutes & 64.8 & 54.83 & 69.59 & 58.53 & 0.079 \\
\hline Nap duration on weekends, minutes & 60.18 & 57.62 & 63.44 & 56.16 & 0.143 \\
\hline Smoking, pack-year & 0.46 & 2.24 & 0.30 & 1.72 & 0.013 \\
\hline Wellness and health score & 15.93 & 2.99 & 15.08 & 3.20 & 0.0001 \\
\hline
\end{tabular}

Before the pandemic period, subjects went to bed on weekends 40 min later than on weekdays $(p<0.0001)$. In the pandemic period, this difference decreased to $26 \mathrm{~min}$ $(p<0.0001)$. In both the pre-pandemic and pandemic periods, subjects woke up $96 \mathrm{~min}$ later on weekends compared to the weekdays $(p<0.0001)$. Before the pandemic, the mean sleep duration every night was $7 \mathrm{~h}$ and $22 \mathrm{~min}$ for the weekdays, which decreased to $6 \mathrm{~h}$ and 44 min during the pandemic. The difference signified a 38 min sleep debt every night. The night sleep duration on weekdays before the pandemic was 33 min shorter than the night sleep duration on weekends $(p<0.0001)$. This difference decreased to 2 min during the pandemic. The mean nap duration was more than one hour, whether on weekends or weekdays, in both the pandemic and the pre-pandemic periods.

Females and males were compared in terms of different lifestyle elements. Although the smoking rate was always significantly worse in males than females, the following lifestyle elements were significantly worse in females than males in both the pre-pandemic and pandemic periods: sleep quality, mood, and physical activity (Table 3). There was no significant difference between females and males in most sleep duration variables. The only exception was the nap duration on weekdays in the pandemic period, which was significantly longer in females than in males (Table 3). 
Table 3. Lifestyle characteristics of participants comparing females and males in the pandemic and pre-pandemic periods.

\begin{tabular}{|c|c|c|c|c|c|c|}
\hline \multirow{2}{*}{ Lifestyle Elements } & \multicolumn{2}{|c|}{ Before Pandemic } & \multirow{2}{*}{$p$ Value } & \multicolumn{2}{|c|}{ During Pandemic } & \multirow{2}{*}{$p$ Value } \\
\hline & Female & Male & & Female & Male & \\
\hline Sleep quality score, out of 70 & 13.36 & 9.71 & 0.006 & 17.01 & 12.65 & 0.008 \\
\hline Mood score, out of 35 & 9.88 & 6.09 & 0.001 & 13.02 & 9.65 & 0.01 \\
\hline Diet score, out of 49 & 13.66 & 12.52 & 0.1 & 14.35 & 13.09 & 0.06 \\
\hline Physical activity, minutes & 19.5 & 22.3 & 0.01 & 8.7 & 18.2 & 0.001 \\
\hline Social activity, days per week & 1.79 & 2.21 & 0.1 & 0.5 & 0.7 & 0.1 \\
\hline Time to go to bed on weekdays & 24:19 a.m. & 24:21 a.m. & 0.9 & 24:49 a.m. & 1:04 a.m. & 0.2 \\
\hline Time to go to bed on weekends & 24:33 a.m. & 1:00 a.m. & 0.8 & 1:17 a.m. & 1:29 a.m. & 0.4 \\
\hline Time to fall asleep, minutes & 22 & 18 & 0.2 & 26.09 & 20.77 & 0.2 \\
\hline Wake-up time on weekdays & 7:32 a.m. & 7:12 a.m. & 0.15 & 7:43 a.m. & 7:30 a.m. & 0.4 \\
\hline Wake-up time on weekends & 9:06 a.m. & 8:53 a.m. & 0.4 & 9:07 a.m. & 9:03 a.m. & 0.8 \\
\hline Night sleep duration on weekdays & 7.76 & 6.69 & 0.8 & 6.95 & 6.49 & 0.2 \\
\hline Night sleep duration on weekends & 7.61 & 7.59 & 0.9 & 7.73 & 7.64 & 0.7 \\
\hline Nap duration on weekdays, minutes & 67.73 & 60.61 & 0.4 & 78.00 & 57.22 & 0.01 \\
\hline Nap duration on weekends, minutes & 60.84 & 59.19 & 0.8 & 65.38 & 60.56 & 0.5 \\
\hline Smoking, pack/year & 0.08 & 1.01 & 0.004 & 0.06 & 0.65 & 0.016 \\
\hline Wellness and health score & 15.95 & 15.91 & 0.9 & 15.10 & 15.06 & 0.9 \\
\hline
\end{tabular}

A total of 17 subjects had confirmed COVID-19 by swab test, of which 10 were female (59\%) and 7 were male (41\%). The most common accompanying disease was hypothyroidism $(5.5 \%)$. Table 4 demonstrates the multivariable linear regression models of the self-rated wellness and health index, compared with the pre-pandemic and pandemic periods. The following variables were left in the pre-pandemic regression model by backward elimination: sex, mood status, physical activity, diet and wake-up time. In the multivariable model built for the pandemic period, mood status, physical activity, diet and wake-up time stayed in the model, but sex was replaced by two other sleep quantity variables, i.e., night sleep duration on weekdays and nap duration on weekdays. The strength of association of pre-planned physical activity and the wellness and health index in the pandemic period was double of that in the pre-pandemic period (Table 4).

Table 4. Multivariable linear regression models of the self-rated wellness and health index comparing the pre-pandemic and pandemic periods.

\begin{tabular}{|c|c|c|c|c|c|c|c|c|}
\hline \multirow{3}{*}{ Lifestyle Elements } & \multicolumn{4}{|c|}{ Before Pandemic Model } & \multicolumn{4}{|c|}{ Covid-19 Pandemic Model } \\
\hline & \multirow{2}{*}{$\beta$} & \multicolumn{2}{|c|}{$95 \%$ CI for $\beta$} & \multirow{2}{*}{$p$ Value } & \multirow{2}{*}{$\beta$} & \multicolumn{2}{|c|}{$95 \%$ CI for $\beta$} & \multirow{2}{*}{$p$ Value } \\
\hline & & Lower & Upper & & & Lower & Upper & \\
\hline Mood score & -0.144 & -0.195 & -0.093 & 0.0001 & -0.101 & -0.147 & -0.055 & 0.0001 \\
\hline Physical activity & 0.012 & 0.001 & 0.023 & 0.035 & 0.023 & 0.006 & 0.04 & 0.01 \\
\hline Diet score & 0.078 & -0.001 & 0.157 & 0.054 & 0.06 & -0.031 & 0.152 & 0.20 \\
\hline Wake-up time on weekdays & -0.279 & -0.541 & -0.018 & 0.037 & -0.183 & -0.424 & 0.059 & 0.15 \\
\hline Sex & 0.731 & -0.078 & 1.54 & 0.076 & \multicolumn{4}{|c|}{ Removed by Backward Elimination } \\
\hline Night sleep duration on weekdays & & & & & 0.049 & 0.0001 & 0.098 & 0.049 \\
\hline Nap duration on weekdays, minutes & & & & & 0.009 & 0.002 & 0.016 & 0.01 \\
\hline \multicolumn{9}{|l|}{ Age, years } \\
\hline \multicolumn{9}{|l|}{ Sleep quality score } \\
\hline Time to go to bed on weekdays & & & & & & & & \\
\hline Time to go to bed on weekends & \multirow{2}{*}{\multicolumn{8}{|c|}{ Removed }} \\
\hline Time to fall asleep, minutes & & & & & & & & \\
\hline Wake-up time on weekends & \multicolumn{4}{|c|}{ By } & \multicolumn{4}{|c|}{ Removed } \\
\hline Night sleep duration on weekends & \multirow{2}{*}{\multicolumn{4}{|c|}{$\begin{array}{l}\text { Backward } \\
\text { Elimination }\end{array}$}} & \multicolumn{4}{|c|}{ By } \\
\hline Nap duration on weekends, minutes & & & & & \multirow{2}{*}{\multicolumn{4}{|c|}{$\begin{array}{l}\text { Backward } \\
\text { Elimination }\end{array}$}} \\
\hline $\begin{array}{l}\text { Nap duration on weekenas, minutes } \\
\text { Snoring }\end{array}$ & & & & & \\
\hline \multicolumn{9}{|l|}{ Social activity } \\
\hline \multicolumn{9}{|l|}{ Smoking, pack/year } \\
\hline \multicolumn{9}{|l|}{ Alcohol } \\
\hline Comorbid conditions & & & & & & & & \\
\hline
\end{tabular}




\section{Discussion}

By comparing the two regression models of the pre-pandemic and pandemic periods, we were able to detect a pattern of significance of sleep duration for the pandemic period model. In our final regression model for the pre-pandemic period, sex, mood status, physical activity, diet and wake-up time were the principal indicators of the wellness and health index, whereas during the pandemic period, two sleep duration variables showed significant associations as well. In practice, however, the heavy burden of the pandemic on the medical system has led to a significant decrease in the participants' sleep quality, mood status and physical activity compared with the pre-pandemic states by $30 \%$, $40 \%$ and $50 \%$, respectively, as shown in Table 2 . The mean sleep quality score before the pandemic was 11.84 out of 70 , which became worse during the pandemic $(15.24 / 70)$. Similarly, the average night sleep duration during the week was $7 \mathrm{~h}$ and $22 \mathrm{~min}$ before the pandemic, which decreased to $6 \mathrm{~h}$ and $44 \mathrm{~min}$ during the pandemic. Sleep quality was also evaluated. It became worse during the pandemic compared to the pre-pandemic state. It was also entered in the multivariable linear regression model, which was removed by a backward elimination process. These series of broken routines and vicious circles have led to Coronasomnia. Although insomnia among healthcare professionals was a serious problem before the COVID-19 pandemic, it is now an enormous disruptive lifestyle factor. The $28 \%$ decrease in quality of sleep along with 38 min of sleep debt during the pandemic period compared to the pre-pandemic state could be the main indicators of health-related well-being in the pandemic period. This finding has been highlighted by the backward elimination multivariable linear regression model. Thirty-eight minutes of sleep debt every night can dramatically deteriorate the well-being, health and performance of healthcare workers in the long term. This is especially important during the pandemic period, the shortage of workers along with high patient loads leading to the fatigue of healthcare workers. Given the current pandemic and the chronic sleep debt, it may take longer to recover than one may think [20,22]. In line with our findings, a study of 1563 healthcare workers during the COVID-19 outbreak found that more than one-third of healthcare workers suffered from insomnia [2]. Sleep insufficiency among healthcare practitioners has been reported by several studies during the current pandemic [32-34]. In another study, 38\% of pediatric healthcare workers suffered from sleep disturbances, and $20 \%$ showed anxiety and depression symptoms [34]. Multiple studies conducted in different parts of the world have shown similar findings among frontline healthcare professionals who are actively fighting COVID-19 [35-44]. In the current medical setting, sleep quality and quantity among healthcare professionals are now much more attention-worthy. Poor sleep can decrease professional performance and increase medical errors and burnout, as demonstrated by various studies [45-48]. It can also disrupt the normal functions of the immune system, resulting in increased susceptibility to COVID-19, which in turn will further increase the pandemic's burden on the medical system and reduce the quality of care $[49,50]$. In addition, sleep insufficiency may lead to more severe anxiety and depression [51]. Mood status was another main indicator of self-rated wellness and health status in our study. Long-term effects of sleep insufficiency are not limited to mood status. Obesity, dyslipidemia, hypertension, diabetes, cardiovascular diseases, cancers, cognitive decline and Alzheimer's disease are some of the most serious long-lasting consequences of a poor sleep habit [52-55] (Liu et al., 2013; Smiley et al., 2019b, 2019a, 2018).

Our study's critical shortcoming was the limited applicability of the self-reported wellness and health index and lifestyle factors in assessing the quality of life of the healthcare professionals; thus, we encourage objective methods of recording staff's wellness and health and their lifestyle in studies to come. The COVID-19 pandemic occurred unexpectedly, and it was not possible to conduct a follow-up study to assess the influence of the pandemic on lifestyle before and after the pandemic. The study was conducted during the COVID-19 pandemic period and required information regarding the current lifestyle during the pandemic period as well as the lifestyle before the pandemic period. The retrospective design was the only way to gather pre-pandemic data about the sample 
and compare it with the pandemic data; however, we acknowledge the limitations of the retrospective design in terms of it being inferior evidence compared to prospective studies. The last pandemic, Spanish flu, which caused a massive loss of human life all over the world, happened one hundred years ago. None of the current active healthcare workers experienced that pandemic personally. The current pandemic was a unique experience for them. A similarly designed study on 699 adults in the USA showed that sleep data recorded years before the pandemic was closely matched with the sleep data of the prepandemic period gathered during the pandemic period [56]. Another study on 7753 adults showed significant changes in lifestyle behaviors during the pandemic compared to the pre-pandemic state [57]. Many lifestyle questions that we asked were about stable habits, and many of the responses were significantly different between the pre-pandemic and pandemic states. Thus, we may assume that subjects, to some extent, were able to recognize changes in their own habits, although we cannot definitely tackle the recall bias, which could be both negative and positive. We used a short questionnaire which limited the amount of information gathered from the healthcare workers. Finally, we believe that implementing new strategies to mitigate the risks associated with declining quality of life among healthcare workers is of the utmost importance, not only in the context of the current pandemic but also as preventative measures for the future. Further studies are needed to illustrate the impact of the current well-being and health index of healthcare professionals on this pandemic's long-term outcomes.

\section{Conclusions}

In conclusion, the decline in healthcare workers' well-being and health state during the COVID-19 outbreak could be strongly associated with several lifestyle factors including sleep insufficiency, less physical activity, lower mood state and worse diet. The outcome of this crisis heavily depends on how the pressure of the current pandemic on healthcare workers is addressed, having in mind that they are directly in contact with the afflicted. Comprehensive strategies need to be employed to prevent further deterioration of staff's quality of life and improve their working conditions.

Author Contributions: Conceptualization, A.S.; formal analysis, A.S.; investigation, M.M., K.S., S.M. (Somayeh Mohammadi), S.M. (Soroush Moradi), M.B. and J.B.; methodology, M.M., K.S., S.M. (Somayeh Mohammadi), S.M. (Soroush Moradi), M.B., J.B. and A.S.; project administration, M.M.; writing—original draft, A.S.; writing—review and editing, M.M., K.S., S.M. (Somayeh Mohammadi), S.M. (Soroush Moradi), M.B. and J.B. All authors have read and agreed to the published version of the manuscript.

Funding: This research received no external funding.

Institutional Review Board Statement: The study was conducted according to the guidelines of the Declaration of Helsinki, and approved by the Institutional Review Board of Qom University of Medical Sciences (protocol code IR.MUQ.REC.1400.161 and date of approval: 26 October 2020).

Informed Consent Statement: Informed consent was obtained from all subjects involved in the study.

Data Availability Statement: Data are available upon request by contacting the corresponding author.

Conflicts of Interest: The authors declare no conflict of interest.

\section{References}

1. Ran, L.; Chen, X.; Wang, Y.; Wu, W.; Zhang, L.; Tan, X. Risk Factors of Healthcare Workers with Corona Virus Disease 2019: A Retrospective Cohort Study in a Designated Hospital of Wuhan in China, Clinical infectious diseases: An official publication of the Infectious Diseases Society of America. Clin. Infect. Dis. 2020. [CrossRef]

2. Zhang, Y.; Ma, Z.F. Impact of the COVID-19 pandemic on mental health and quality of life among local residents in Liaoning Province, China: A cross-sectional study. Int. J. Environ. Res. Public Health 2020, 17, 2381. [CrossRef]

3. Lai, J.; Ma, S.; Wang, Y.; Cai, Z.; Hu, J.; Wei, N.; Wu, J.; Du, H.; Chen, T.; Li, R.; et al. Factors Associated With Mental Health Outcomes Among Health Care Workers Exposed to Coronavirus Disease 2019. JAMA Netw. Open 2020, 3, e203976. [CrossRef] [PubMed] 
4. Maunder, R.; Hunter, J.; Vincent, L.; Bennett, J.; Peladeau, N.; Leszcz, M.; Sadavoy, J.; Verhaeghe, L.M.; Steinberg, R.; Mazzulli, T. The immediate psychological and occupational impact of the 2003 SARS outbreak in a teaching hospital. Cmaj 2003, 168, 1245-1251. [PubMed]

5. Belingheri, M.; Paladino, M.E.; Riva, M.A. Working schedule, sleep quality and susceptibility to COVID-19 in healthcare workers, Clinical infectious diseases: An official publication of the Infectious Diseases Society of America. Clin. Infect. Dis. 2020. [CrossRef]

6. Lachytova, M.; Katreniakova, Z.; Mikula, P.; Jendrichovsky, M.; Nagyova, I. Associations between self-rated health, mental health problems and physical inactivity among urban adolescents. Eur. J. Public Health 2017, 27, 984-989. [CrossRef] [PubMed]

7. Granger, E.; Williams, G.; Di Nardom, F.; Harrison, A.; Verma, A. The relationship between physical activity and self-rated health status in European adolescents: Results of the EURO-URHIS 2 survey. Eur. J. Public Health 2017, 27, 107-111. [CrossRef]

8. Han, M.A.; Kim, K.S.; Park, J.; Kang, M.G.; Ryu, S.Y. Association between levels of physical activity and poor self-rated health in Korean adults: The Third Korea National Health and Nutrition Examination Survey (KNHANES), 2005. Public Health 2009, 123, 665-669. [CrossRef]

9. Richards, J.; Jiang, X.; Kelly, P.; Chau, J.; Bauman, A.; Ding, D. Don't worry, be happy: Cross-sectional associations between physical activity and happiness in 15 European countries. BMC Public Health 2015, 15, 53. [CrossRef]

10. Smiley, A.; Ramos, W.D.; Elliott, L.M.; Wolter, S. Association between trail use and self-rated wellness and health. BMC Public Health 2020, 20, 128. [CrossRef]

11. Södergren, M.; Sundquist, J.; Johansson, S.E.; Sundquist, K. Physical activity, exercise and self-rated health: A population-based study from Sweden. BMC Public Health 2008, 8, 352. [CrossRef] [PubMed]

12. Wolter, S.A.; Ramos, W.D.; Eilliott, L.; Smiley, A. Investigating the Health Benefits of Trail Use, a Perspective from Park Practitioners. Recreat. Parks Tour. Public Health 2019, 3, 97-112. [CrossRef]

13. Darviri, C.; Fouka, G.; Gnardellis, C.; Artemiadis, A.K.; Tigani, X.; Alexopoulos, E.C. Determinants of self-rated health in a representative sample of a rural population: A cross-sectional study in Greece. Int. J. Environ. Res. Public Health 2012, 9, 943-954. [CrossRef]

14. Hsieh, H.-H.; Chang, C.-M.; Liu, L.-W.; Huang, H.C. The Relative Contribution of Dietary Habits, Leisure-Time Exercise, Exercise Attitude, and Body Mass Index to Self-Rated Health among College Students in Taiwan. Int. J. Environ. Res. Public Health 2018, 15, 967. [CrossRef]

15. Molarius, A.; Berglund, K.; Eriksson, C.; Lambe, M.; Nordström, E.; Eriksson, H.G.; Feldman, I. Socioeconomic conditions, lifestyle factors, and self-rated health among men and women in Sweden. Eur. J. Public Health 2007, 17, 125-133. [CrossRef]

16. Dong, W.; Wan, J.; Xu, Y.; Chen, C.; Bai, G.; Fang, L.; Sun, A.; Yang, Y.; Wang, Y. Determinants of self-rated health among shanghai elders: A cross-sectional study. BMC Public Health 2017, 17, 807. [CrossRef]

17. Esmaeili, A.; Masjedi, M.; Ani, A.; Farajzadegan, Z.; Behbahani, A.; Dashti, M.; Emami, M.H. New insights of anti-depressant therapy in the management of ulcerative colitis. Gastroenterology 2008, 134, 100. [CrossRef]

18. Girón, P. Determinants of self-rated health in Spain: Differences by age groups for adults. Eur. J. Public Health 2012, 22, 36-40. [CrossRef] [PubMed]

19. Smiley, A.; Ramos, W.D.; Elliott, L.M.; Wolter, S. Comparing the Trail Users with Trail Non-Users on Physical Activity, Sleep, Mood and Well-Being Index. Int. J. Environ. Res. Public Health 2020, 17, 6225. [CrossRef]

20. Kang, J.; Noh, W.; Lee, Y. Sleep quality among shift-work nurses: A systematic review and meta-analysis. Appl. Nurs. Res. 2020, 52, 151227. [CrossRef]

21. Masoumi, M.; Tabaraii, R.; Shakiba, S.; Shakeri, M.; Smiley, A. Association of lifestyle elements with self-rated wellness and health status in patients with Behcet's disease. BMC Rheumatol. 2020, 4, 49. [CrossRef]

22. Tabaraii, R.; Masoumi, M.; Bagherzadeh-Fard, M.; Yazdanifar, M.A.; Balasi, J.; Smiley, A. Association of lifestyle and disease characteristics with self-rated wellness/health score in patients with rheumatoid arthritis. BMC Rheumatol. 2021, 5, 55. [CrossRef]

23. Parry, D.A.; Oeppen, R.S.; Amin, M.S.A.; Brennan, P.A. Sleep: Its importance and the effects of deprivation on surgeons and other healthcare professionals. Br J. Oral. Maxillofac. Surg. 2018, 56, 663-666. [CrossRef]

24. Dugan, A. Fast Food Still Major Part of U.S. Diet. Gallup Poll Brief. 2013, 2013, 2.

25. Kapteyn, A.; Lee, J.; Tassot CVonkova, H.; Zamarro, G. Dimensions of Subjective Well-Being. Soc. Indic. Res. 2015, 123, 625-660. [CrossRef] [PubMed]

26. Natale, V.; Fabbri, M.; Tonetti, L.; Martoni, M. Psychometric goodness of the Mini Sleep Questionnaire. Psychiatry Clin. Neurosci. 2014, 68, 568-573. [CrossRef] [PubMed]

27. Nordgren, L.; Söderlund, A. Social support, self-rated health and low mood in people on sick leave due to heart failure: A cross-sectional study. Scand J. Public Health 2018, 46, 606-612. [CrossRef] [PubMed]

28. Karageorghis, C.I.; Vencato, M.M.; Chatzisarantis, N.L.D.; Carron, A.V. Development and initial validation of the Brunel lifestyle physical activity questionnaire. Br. J. Sports Med. 2005, 39, e23. [CrossRef] [PubMed]

29. Steptoe, A.; Wardle, J.; Lipsey, Z.; Mills, R.; Oliver, G.; Jarvis, M.; Kirschbaum, C. A longitudinal study of work load and variations in psychological well- being, cortisol, smoking, and alcohol consumption. Ann. Behav. Med. 1998, 20, 84-91. [CrossRef]

30. DeSalvo, K.B.; Bloser, N.; Reynolds, K.; He, J.; Muntner, P. Mortality prediction with a single general self-rated health question: A meta-analysis. J. Gen. Intern. Med. 2006, 21, 267-275. [CrossRef]

31. Pop, L.M.; Iorga, M.; Șipoș, L.R.; Iurcov, R. Gender Differences in Healthy Lifestyle, Body Consciousness, and the Use of Social Networks among Medical Students. Med. Kaunas Lith. 2021, 57, 648. [CrossRef] [PubMed] 
32. Franceschini, C.; Musetti, A.; Zenesini, C.; Palagini, L.; Scarpelli, S.; Quattropani, M.C.; Lenzo, V.; Freda, M.F.; Lemmo, D.; Vegni, E.; et al. Poor Sleep Quality and Its Consequences on Mental Health During the COVID-19 Lockdown in Italy. Front. Psychol. 2020, 11, 574475. [CrossRef] [PubMed]

33. Mello, M.T.D.; Silva, A.; de Guerreiro, R.C.; da-Silva, F.R.; Esteves, A.M.; Poyares, D.; Piovezan, R.; Treptow, E.; Starling, M.; Rosa, D.S.; et al. Sleep and COVID-19: Considerations about immunity, pathophysiology, and treatment. Sleep Sci. 2020, 13, 199-209. [CrossRef] [PubMed]

34. Wang, S.; Xie, L.; Xu, Y.; Yu, S.; Yao, B.; Xiang, D. Sleep disturbances among medical workers during the outbreak of COVID-2019, Occupational Medicine. Occup. Med. Lond. 2020. [CrossRef]

35. Batra, K.; Singh, T.P.; Sharma, M.; Batra, R.; Schvaneveldt, N. Investigating the Psychological Impact of COVID-19 among Healthcare Workers: A Meta-Analysis. Int. J. Environ. Res. Public Health 2020, 17, 9096. [CrossRef]

36. Cénat, J.M.; Blais-Rochette, C.; Kokou-Kpolou, C.K.; Noorishad, P.-G.; Mukunzi, J.N.; McIntee, S.-E.; Dalexis, R.D.; Goulet, M.-A.; Labelle, P.R. Prevalence of symptoms of depression, anxiety, insomnia, posttraumatic stress disorder, and psychological distress among populations affected by the COVID-19 pandemic: A systematic review and meta-analysis. Psychiatry Res. 2020, 295, 113599. [CrossRef] [PubMed]

37. Krishnamoorthy, Y.; Nagarajan, R.; Saya, G.K.; Menon, V. Prevalence of psychological morbidities among general population, healthcare workers and COVID-19 patients amidst the COVID-19 pandemic: A systematic review and meta-analysis. Psychiatry Res. 2020, 293, 113382. [CrossRef]

38. Liang, Y.; Wu, K.; Zhou Yongjie Huang, X.; Zhou Yueyue Liu, Z. Mental Health in Frontline Medical Workers during the 2019 Novel Coronavirus Disease Epidemic in China: A Comparison with the General Population. Int. J. Env. Res. Public Health 2020, 17, 6550. [CrossRef]

39. Liu, C.-Y.; Yang, Y.-Z.; Zhang, X.-M.; Xu, X.; Dou, Q.-L.; Zhang, W.-W.; Cheng, A.S.K. The prevalence and influencing factors in anxiety in medical workers fighting COVID-19 in China: A cross-sectional survey. Epidemiol Infect. 2020, 148, e98. [CrossRef]

40. Machado, A.S.; Pereira, E.; Grangeia, R.; Norton, P. Mental Health Support to Health Care Workers During COVID-19 Pandemic: Is the Front Line Necessarily the Priority Line? J. Occup. Environ. Med. 2020, 62, e677-e678. [CrossRef]

41. Pappa, S.; Ntella, V.; Giannakas, T.; Giannakoulis, V.G.; Papoutsi, E.; Katsaounou, P. Prevalence of depression, anxiety, and insomnia among healthcare workers during the COVID-19 pandemic: A systematic review and meta-analysis. Brain Behav. Immun. 2020, 88, 901-907. [CrossRef] [PubMed]

42. Salari, N.; Khazaie, H.; Hosseinian-Far, A.; Khaledi-Paveh, B.; Kazeminia, M.; Mohammadi, M.; Shohaimi, S.; Daneshkhah, A.; Eskandari, S. The prevalence of stress, anxiety and depression within front-line healthcare workers caring for COVID-19 patients: A systematic review and meta-regression. Hum. Resour. Health 2020, 18, 100. [CrossRef]

43. Wang, L.-Q.; Zhang Meng Liu, G.-M.; Nan, S.-Y.; Li, T.; Xu, L.; Xue, Y.; Zhang Min Wang, L.; Qu, Y.-D.; Liu, F. Psychological impact of coronavirus disease (2019) (COVID-19) epidemic on medical staff in different posts in China: A multicenter study. J. Psychiatr. Res. 2020, 129, 198-205. [CrossRef] [PubMed]

44. Woon, L.S.-C.; Sidi, H.; Nik Jaafar, N.R.; Leong Bin Abdullah, M.F.I. Mental Health Status of University Healthcare Workers during the COVID-19 Pandemic: A Post-Movement Lockdown Assessment. Int. J. Environ. Res. Public Health 2020, $17,9155$. [CrossRef]

45. Aran, A.; Wasserteil, N.; Gross, I.; Mendlovic, J.; Pollak, Y. Medical Decisions of Pediatric Residents Turn Riskier after a 24-Hour Call with No Sleep. Med. Decis. Mak. 2017, 37, 127-133. [CrossRef]

46. Samkoff, J.S.; Jacques, C.H. A review of studies concerning effects of sleep deprivation and fatigue on residents' performance. Acad. Med. 1991, 66, 687-693. [CrossRef] [PubMed]

47. Trockel, M.T.; Menon, N.K.; Rowe, S.G.; Stewart, M.T.; Smith, R.; Lu, M.; Kim, P.K.; Quinn, M.A.; Lawrence, E.; Marchalik, D.; et al. Assessment of Physician Sleep and Wellness, Burnout, and Clinically Significant Medical Errors. JAMA Netw. Open 2020, 3, e2028111. [CrossRef] [PubMed]

48. Welle, D.; Trockel, M.T.; Hamidi, M.S.; Hickson, G.B.; Menon, N.K.; Shanafelt, T.D.; Cooper, W.O. Association of Occupational Distress and Sleep-Related Impairment in Physicians With Unsolicited Patient Complaints. Mayo Clin. Proc. 2020, 95, 719-726. [CrossRef] [PubMed]

49. Meira ECruz, M.; Miyazawa, M.; Gozal, D. Putative contributions of circadian clock and sleep in the context of SARS-CoV-2 infection. Eur. Respir. J. 2020, 55. [CrossRef] [PubMed]

50. Xiao, H.; Zhang, Y.; Kong, D.; Li, S.; Yang, N. The effects of social support on sleep quality of medical staff treating patients with coronavirus disease 2019(COVID-19) in January and February 2020 in China. Med Sci. Monit. 2020, 26, e923549. [CrossRef] [PubMed]

51. Al-Ajlouni, Y.A.; Park, S.H.; Alawa, J.; Shamaileh, G.; Bawab, A.; El-Sadr, W.M.; Duncan, D.T. Anxiety and depressive symptoms are associated with poor sleep health during a period of COVID-19-induced nationwide lockdown: A cross-sectional analysis of adults in Jordan. BMJ Open 2020, 10, e041995. [CrossRef] [PubMed]

52. Liu, Y.; Wheaton, A.G.; Chapman, D.P.; Croft, J.B. Sleep Duration and Chronic Diseases among US Adults Age 45 Years and Older: Evidence From the 2010 Behavioral Risk Factor Surveillance System. Sleep 2013, 36, 1421-1427. [CrossRef] [PubMed]

53. Smiley, A.; King, D.; Bidulescu, A. The Association between Sleep Duration and Metabolic Syndrome: The NHANES $2013 / 2014$. Nutrients 2019, 11, 2582. [CrossRef] [PubMed] 
54. Smiley, A.; King, D.; Harezlak, J.; Dinh, P.; Bidulescu, A. The association between sleep duration and lipid profiles: The NHANES 2013-2014. J. Diabetes Metab. Disord. 2019, 18, 315-322. [CrossRef] [PubMed]

55. Smiley, A.; Wolter, S.; Nissan, D. Mechanisms of Association of Sleep and Metabolic Syndrome. J. Med.-Clin. Res. Rev. 2019, 3, 1-9. [CrossRef]

56. Gao, C.; Scullin, M.K. Sleep health early in the coronavirus disease 2019 (COVID-19) outbreak in the United States: Integrating longitudinal, cross-sectional, and retrospective recall data. Sleep Med. 2020, 73, 1-10. Available online: https: / www.sciencedirect. com/science/article/pii/S1389945720302999 (accessed on 15 April 2021). [CrossRef] [PubMed]

57. Flanagan, E.W.; Beyl, R.A.; Fearnbach, S.N.; Altazan, A.D.; Martin, C.K.; Redman, L.M. The Impact of COVID-19 Stay-At-Home Orders on Health Behaviors in Adults. Obes. Silver Spring 2021, 29, 438-445. [CrossRef] 